\title{
My favorite topic...health
}

\author{
Stephen B Hanauer
}

In a recent issue of the New England Journal of Medicine, Susan Okie, MD wrote a Perspective on "The Employer as Health Coach" depicting ways in which companies are attempting to sponsor health-promotion programs for their employees (New Engl J Med [2007] 357: 14651469). Regular readers of this column will know that I have previously written about employers supporting the idea that their employees eat healthy food.

Given that the US health-care system is funded, primarily, by employers it would seem that there are two very basic reasons why it is in corporate interest to promote good health amongst employees. The first reason is to reduce health-care related expenditures. The second reason is that healthy employees are more productive and take less time off work sick.

There are multiple strategies that employers can use to persuade employees to change any unhealthy habits they might have. In addition to subsidizing the cost of healthy foods in cafeterias, companies can offer annual health-risk questionnaires and screening tests to identify risk factors, along the lines of the draft recommendations of the CDC Task Force on Community Preventive Services (http:// www.thecommunityguide.org/). These measures include the reduction of tobacco and alcohol use, improving measurements of physical activity, use of seatbelts, reducing dietary intake of fat, reducing elevated blood pressure, reducing elevated cholesterol levels, and so on. Employers can offer incentives for participation in risk-reduction programs, provide free or reduced-cost preventive services at work, offer ....economic

benefits to

the 'bottom-

line' can be

obtained by

increased

productivity

and overall

lower health-

care costs.

SB Hanauer is Editorin-Chief of Nature Clinical Practice Gastroenterology \& Hepatology.

\section{Competing interests}

The author declared no competing interests.

www.nature.com/clinicalpractice doi:10.1038/ncpgasthep1002 special programs for stressed or depressed workers, and open on-site fitness facilities.

To be effective these programs need to be comprehensive, yet tailored to the employee population and marketed creatively with the support of top management. There are potential risks of discrimination against employees, but the use of incentives (for positive efforts) rather than punishments are favored by most companies. Several companies are already refusing to hire workers who smoke cigarettes; testing for the use of other drugs is not uncommon and is certainly considered legal. Others companies, such as Wal-Mart, are considering whether all jobs should include tasks involving physical activity to discourage applications from unhealthy people.

Creative management has numerous means to encourage healthy habits and help modify existing health risks. Potential offerings include: reductions in health insurance premiums for workers who take steps to reduce the risk of illness (e.g. participation in health-management, smoking cessation, or weight-management programs); on-site or subsidized fitness programs; subsidized healthy foods in corporate dining facilities and, for larger companies, on-site clinics, pharmacies, and dentists. Many companies are already offering annual flu shots. Similar incentives need to be provided for individuals who already maintain healthy lifestyles. For smaller organizations, the impact of having even a few employees with preventable, high-cost illnesses can be 'catastrophic'; by adapting the programs offered by larger organizations, economic benefits to the 'bottom-line' can be obtained by increased productivity and overall lower health-care costs. 